\title{
Impactos do avanço da soja no balanço de radiação no leste da Amazônia
}

\author{
Paulo Jorge de Oliveira Ponte de SOUZA ${ }^{1}$, Edson José Paulino da ROCHA ${ }^{2}$, Aristides RIBEIRO ${ }^{3}$ \\ RESUMO \\ O desmatamento da Amazônia, em especial para o uso da pecuária, tem sido explorado por diversos pesquisadores, os quais \\ têm apontado como conseqüência, sérios problemas ambientais. O contínuo avanço da fronteira agrícola sobre as áreas de \\ pecuária na Amazônia, e mesmo sobre áreas nativas, merece atençáo pelo fato de poucos estudos terem sido realizados com o \\ intuito de investigar quais os prováveis impactos ambientais da presença da monocultura da soja na regiáo. Este trabalho teve \\ como objetivo avaliar os impactos nos componentes do balanço de radiação devido à nova mudança no uso da terra em uma \\ área de avanço da fronteira agrícola no leste da Amazônia. Realizaram-se experimentos micrometeorológicos no município de \\ Paragominas-PA em uma área de cultivo de soja (Glycine max (L.) Merrill) e em uma área do ecossistema florestal localizada na \\ Floresta Nacional de Caxiuanã em Melgaço-PA nos anos de 2006 e 2007. Durante o ciclo da soja o impacto médio encontrado \\ representou uma redução $17,9 \%$ no saldo de radiação em relação ao ecossistema de floresta natural. Durante a entressafra \\ observou-se um impacto negativo no saldo de radiaçáo de $15,5 \%$. Os principais forçantes deste impacto foram o maior albedo \\ da soja e a perda de radiaçáo de onda longa em relação à cobertura original. Ressalta-se que apesar do maior impacto ocorrer \\ durante o ciclo da cultura, o tempo de ocorrência deste impacto negativo restringe-se a apenas $1 / 3$ do ano, o que, implica em \\ maior impacto da entressafra no saldo de energia em termos cumulativos.
}

PALAVRAS-CHAVE: Soja, Mudanças climáticas, Mudanças de uso da terra

\section{Impacts of soybean expansion on radiation balance in eastern Amazon}

\section{ABSTRACT}

The deforestation of the Amazon, especially for pasture use, has been explored by several researchers who have pointed out as a consequence, serious environmental problems. The continuous expansion of agriculture on areas of cattle ranching in the Amazon, as well as on native areas, must be seen with caution since few studies have been conducted in order to investigate which probable environmental impacts can be generated due to the presence of soybean monoculture in the region. This study evaluates the local impacts of the replacement of forest by soybean (Glycine max (L.) Merrill) on radiation balance components in an area that represents the agricultural border advancement in Amazonia. A micrometeorological experiment was installed in an area of soybean cultivation in Paragominas-PA and data from forest ecosystems were collected in Caxiuaná forests located in Melgaço-PA both during 2006 and 2007. During the soybean growing season the mean impact found in net radiation represented a reduction of $17.9 \%$ of the value commonly observed in the forest. During the off-season the impact on net radiation was $15.5 \%$. Principal mechanisms that control these impacts were associated with the high soybean albedo and high loss of long wave radiation. Although the greatest impact occurs during the crop growing season, the time of occurrence of this negative effect is restricted to only $1 / 3$ of the year, which leads to a higher impact of the off-season on energy balance in cumulative terms.

KEYWORDS: Soybean, climate change, Land use changes.

\footnotetext{
1 Universidade Federal Rural da Amazônia - UFRA, Instituto Sócio Ambiental e dos Recursos Hídricos - ISARH, Av Presidente Tancredo Neves 2501, Montese, CEP 66.077-901, Belém-PA, Brasil. Fone (91) 3210 5140. paulo.jorge@ufra.edu.br

2 Universidade Federal do Pará- UFPa, Faculdade de Meteorologia-FAMET. Rua Augusto Correa 01, CEP 66075-110, Belém-PA, Brasil. eprocha@ufpa.br

${ }^{3}$ Universidade Federal de Viçosa - UFV, Av. P.H. Rolfs s/n, CEP 36570-000, Viçosa-MG, Brasil. ribeiro@ufv.br
} 


\section{INTRODUÇAO}

Vários trabalhos sobre a mudança do uso da terra na Amazônia têm mostrado que uma drástica conversão da cobertura vegetal natural pode ocasionar sérias alteraçōes hidrológicas e climáticas regionais (Von Randow et al. 2004; Costa e Yanagi 2006; Correia et al. 2006).

A maioria destes trabalhos trata, porém de simulaçóes da substituição da floresta nativa por pastagem, prática que predominou nas décadas de 70,80 e 90 . A presença do monocultivo da soja na Amazônia, considerada como a principal responsável pelo avanço da fronteira agrícola na região, levanta críticas e duvidas sobre os prováveis impactos ambientais decorrentes desta prática (Fearnside 2001; Simon e Garagorry 2005; Pongratz et al. 2006) por ser um novo modelo de uso da terra, pouco estudado pela comunidade científica.

Segundo Costa e Foley (2000) o processo de desmatamento reduz a capacidade da superfície em manter elevadas taxas de evapotranspiração. $\mathrm{O}$ uso da terra para fins agrícolas ocasiona mudanças mais drásticas nos processos de trocas gasosas entre a superfície e atmosfera devido à contínua mudança na arquitetura da vegetação, e consequentemente na condutância da superfície ao transporte de vapor d'água, no sistema radicular e no albedo da superfície, este último, considerado um dos mais importantes controladores da convecção nos trópicos (Berbet e Costa 2003).

Estas características e a própria dinâmica existente na estrutura física da vegetação são comumente observadas em culturas anuais como no caso da mandioca (Giambelluca et al. 1997), arroz (Sakai et al. 2004) e soja (Souza et al. 2008; Souza et al. 2011) mas normalmente não são consideradas nos modelos de circulação geral e de meso-escala que tentam reproduzir impactos decorrentes do uso da terra (Cohen $e t$ al. 2007), levando a possíveis erros na estimativa do processo de trocas gasosas entre a atmosfera e a superfície vegetada.

Costa et al. (2007) e Sampaio et al. (2007) utilizando modelos globais em uma escala regional simularam possíveis impactos do avanço da soja no clima da Amazônia, e encontraram uma considerável redução na precipitaçáo da regiâo. Resultados obtidos por Pongratz et al. (2006) mostram que o tipo de cobertura vegetal implantada após o desmatamento é um importante controlador dos impactos gerados neste processo devido aos diferentes efeitos gerados por fatores de ordem morfológica e fisiológica.

Resultados observacionais de Souza et al. (2011) indicam reduçóes nos fluxos de calor latente (LE) e sensível (H) da ordem de 9 e $27 \%$, respectivamente, durante o período de crescimento da soja em comparação com ecossistemas naturais. No entanto, os autores identificam a entressafra como sendo o período responsável por impactos mais significativos, com reduçóes de 78\% em LE e aumento de $84 \%$ em H decorrente da ausência de cobertura vegetal durante esta época do ano.

Avaliar localmente os possíveis impactos no balanço de radiação local em decorrência do avanço da soja na regiāo é extremamente importante, uma vez que o processo de interação radiativo existente entre a superfície e atmosfera é um dos principais controladores da precipitação da regiáo sendo também considerada como um dos principais forçantes de modelos climáticos (Berbet e Costa 2003). O objetivo desta pesquisa foi quantificar as alteraçóes nos componentes do balanço de radiação em função do novo padrão de mudança do uso da terra em uma área de avanço da fronteira agrícola na Amazônia.

\section{MATERIAL E MÉTODOS}

\section{Ecossistema de soja}

O experimento conduzido no ecossistema de soja ocorreu no município de Paragominas, situado na região nordeste do Estado do Pará. Isto se justifica pelo fato desta região ter apresentado uma grande expansão do cultivo da soja nos últimos anos. A área com plantio de soja ocupou uma extensão de 200 ha, localizada na latitude $02^{\circ} 59^{\prime} 08^{\prime \prime} \mathrm{S}$ e longitude 47०19'57" W.

O experimento foi realizado em 2006 e 2007, sendo utilizada a variedade BRS Tracajá (cultivar de ciclo intermediário). Toda a área foi plantada mecanicamente com espaçamento de $0,5 \mathrm{~m}$ entre fileiras e de $0,1 \mathrm{~m}$ entre plantas. A semeadura foi realizada em 05 e 23 de fevereiro e a colheita final foi feita no dia 15 e 21 de Junho de 2006 e 2007 , respectivamente. $\mathrm{O}$ desenvolvimento da cultura foi avaliado diariamente usando a classificação dos estádios proposta por Fehr et al. (1971), onde as diferentes fases fenológicas são representadas pelos símbolos $\mathrm{V}$ para o período vegetativo e $\mathrm{R}$ para período reprodutivo, como a seguir: $\mathrm{VE}$ a emergência, Vn todo o período vegetativo, $\mathrm{R} 1$ a $\mathrm{R} 2$ a fase de florescimento, R3 a R4 o período de formação de vagem, R5 o inicio de enchimento de grãos, R6 o enchimento pleno e R7 a R8 o período de maturação da cultura.

Uma torre micrometeorologica de três metros de altura foi montada no centro da área, na qual foram instalados sensores para registro dos perfis de temperatura e umidade relativa do ar e vento (3 níveis). O perfil da temperatura do solo também foi medido (4 níveis). Foram ainda instalados sensores de precipitaçáo, direçấo do vento, radiação solar (incidente, refletida e transmitida ao solo), saldo de radiação; radiação fotossinteticamente ativa (incidente, refletida e transmitida ao solo) e fluxo do calor no solo. Para aquisiçáo e registro dos dados meteorológicos foi utilizado um datalogger CR10X e um multiplexador AM416. Utilizou-se uma bordadura de 1:100, para garantir boa representatividade na coleta de dados. 


\section{Ecossistema florestal}

Os dados referentes ao ecossistema florestal foram obtidos na Floresta Nacional de Caxiuanã, localizada na parte central do estado do Pará, em área pertencente ao Arquipélago de Marajó. As coordenadas geográficas do

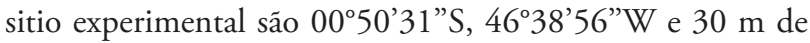
altitude, cuja floresta possui um dossel com altura média de $36 \mathrm{~m}$. O distanciamento entre o sítio de floresta natural e o de soja é de aproximadamente dois graus de latitude $(\approx 500$ $\mathrm{km}$ longitudinalmente). Tal fato pode ser considerado como um importante fator condicionante das possíveis diferenças encontradas, uma vez que regióes mais próximas ao equador sofrem forte influencia de fenômenos como a zona de convergência intertropical - ZCIT (Querino et al. 2006).

Foram utilizados dados médios das mesmas variáveis medidas no ecossistema de soja, obtidos por intermédio de uma estaçáo meteorológica automática instalada em uma torre de $54 \mathrm{~m}$ de altura. $\mathrm{O}$ período de dados utilizados no trabalho correspondeu aos mesmos do experimento da soja, entre fevereiro e junho de 2006 e 2007.

Para analisar o período de entressafra, foram utilizados dados correspondentes aos meses de julho a novembro do ano de 2007 na área de produção de soja e dados correspondente ao mesmo período no ecossistema florestal devido ser o único período disponível na área de soja.

Os componentes do balanço de onda curta, radiação solar incidente $\left(S_{\text {in }}\right)$ e refletida $\left(S_{\text {our }}\right)$ assim como o saldo global de radiação $\left(R_{\text {ner }}\right)$ foram monitorados continuamente durante o período de safra e entressafra nos dois locais de estudos. O saldo radiaçáo de onda longa $\left(\mathrm{L}_{\text {nee }}\right)$ foi medido diretamente no ecossistema de floresta, mas na área de produção de soja foi obtido como resíduo do balanço global de radiaçáo, devido à inexistência de equipamentos apropriados para sua medição. Utilizou-se o teste t de student ao nível de 5\% e 1\% de probabilidade para verificar a significância das diferenças entre as médias das variáveis monitoradas nos dois ecossistemas.

\section{RESULTADOS E DISCUSSÃO}

\section{Impactos durante o período de crescimento da soja}

A Figura 1 apresenta a variação média dos componentes do balanço de radiaçấo nas diferentes fases do desenvolvimento nos dois anos de estudo em ambos os ecossistemas.

A radiaçáo incidente no ecossistema de soja foi sempre superior à observada no ecossistema florestal (Figura 1A), apresentando uma diferença média entre 4 a $21 \%$. Isso pode estar diretamente associada ao diferente grau de nebulosidade observado entre os dois ecossistemas já que por estar mais próximo ao equador, o ecossistema florestal deveria apresentar maior radiação incidente. Este fato corrobora a importância secundária do fator climático latitude como regulador da forçante climática para ambos os locais, sugerindo existir outros fatores condicionantes de ordem local. A menor incidência de radiaçáo solar sobre o ecossistema florestal pode

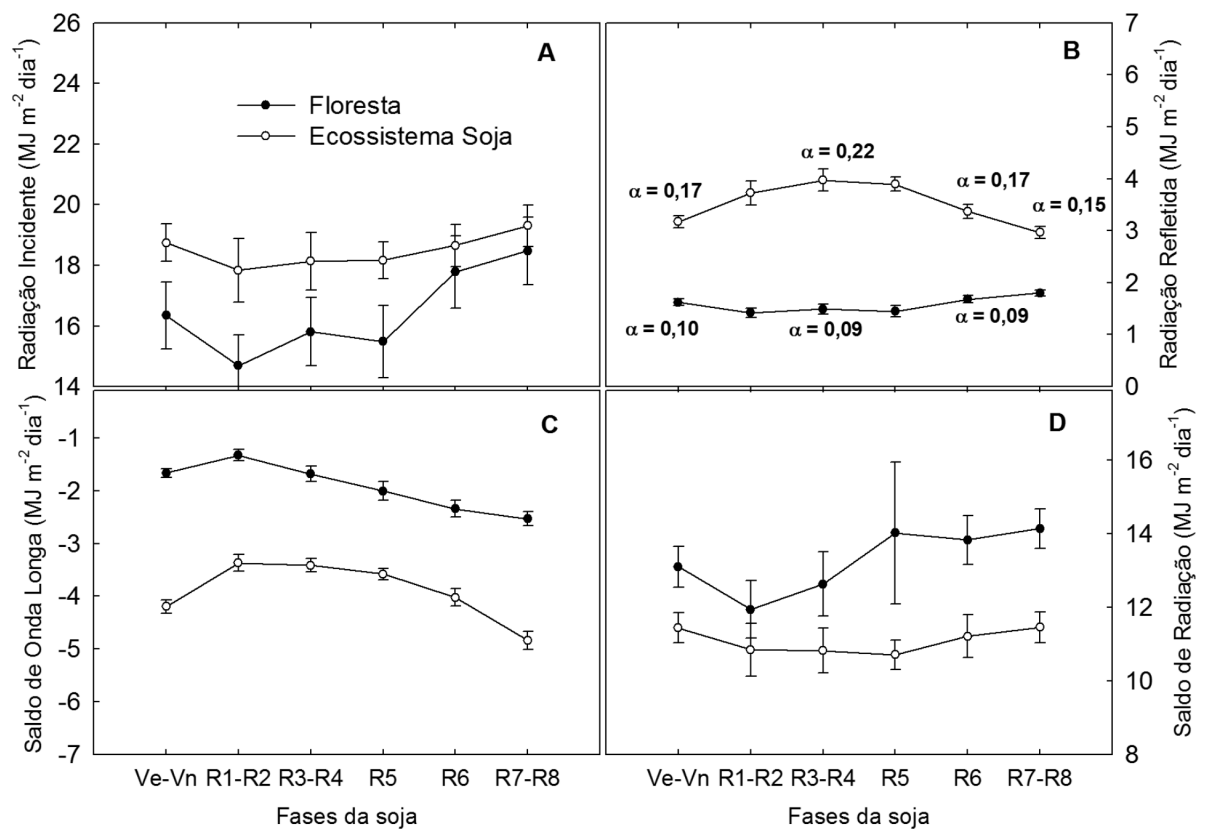

Figura 1 - Médias dos anos de 2006 e 2007 da radiação solar incidente (A), radiação solar refletida (B), saldo de ondas longas (C) e saldo de radiação (D) durante 0 ciclo da soja e no período correspondente no ecossistema de floresta. Barras verticais representam 0 erro padrão; $\alpha=$ albedo 
estar associada à presença de uma atmosfera mais úmida e de maior nebulosidade (Silva Dias et al. 2005; Silva Dias 2006), fato este também constatado por Querino et al. (2006) ao comparar floresta e pastagem na Amazônia, já que a umidade atmosférica é um dos principais absorvedores da radiação solar, principalmente no espectro do infravermelho próximo.

Galvão e Fisch (2000) e Souza Filho et al. (2006) adotaram um critério analítico para se determinar o grau de nebulosidade na região Amazônia. Este critério se baseia na razão entre as irradiâncias solar global e extraterrestre, onde valores abaixo de 0,35 representam dias nublados e valores acima de 0,5 dias de céu claro. Esta razão, obtida com dados do experimento de 2007 (Figura 2), foi sempre superior na área de soja, tanto durante o ciclo como na entressafra, indicando que na regiáo de floresta a atmosfera apresentava maior nebulosidade, influenciando tanto a incidência de radiação como também o saldo de ondas longas.

Ao se comparar a radiação refletida pela superfície nos dois ecossistemas, percebe-se que durante grande parte do período de safra, 64 dias em média, há um aumento de mais de 100\% na radiação refletida ao se mudar a cobertura florestal para soja (Figura 1B e Tabela 1), como consequiência do elevado albedo da soja entre as fases de florescimento (R1) e enchimento pleno do gráo (R6) (Souza et al. 2010). O aumento reportado na radiação refletida devido à mudança no uso da terra na Amazônia para pastagem foi de 58\% (Von Randow et al. 2004) e de $30 \%$ para o cultivo de mandioca (Giambelluca et al. 1997), o que evidencia o baixo poder refletivo destas culturas em comparação ao monocultivo da soja.

A diferença observada no saldo de ondas longas entre os dois ecossistemas acompanhou o crescimento da soja, sendo mais intensa durante a fase vegetativa $(\mathrm{VE}-\mathrm{Vn})$ e na maturação

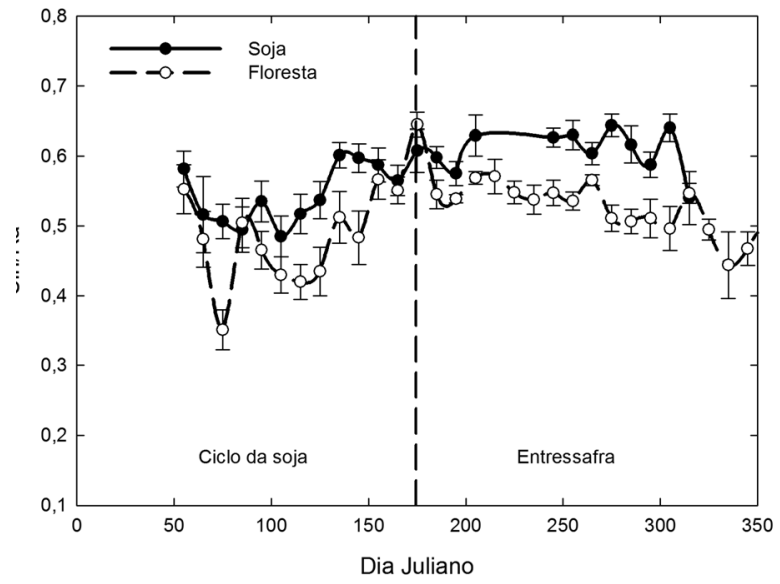

Figura 2 - Média decendial da razão entre radiação global (Sin) e extraterrestre (Ra) ao longo do ano (2006 e 2007) nos ecossistemas de soja e floresta. Barras verticais representam 0 erro padrão.
(R7-R8) (Tabela 1). Nestes dois períodos a perda de energia na forma de ondas longas pela soja foi superior à perda na forma onda curta. Esta variaçấo na emissão de ondas longas pela superfície coberta com a soja é atribuída à variação no índice de área foliar (IAF) da cultura associado à mudança na exposição do solo, conforme também reportado por Fontana et al. (1991) para a soja no Rio Grande do Sul.

Tabela 1 - Diferença média absoluta nos componentes do balanço de ondas curtas e ondas longas entre os ecossistemas de Floresta e de Soja na Amazônia em 2006 e 2007.

\begin{tabular}{lcccr}
\hline & \multicolumn{4}{c}{ Diferença } \\
\hline Fases & $\begin{array}{c}\text { Duração } \\
\text { (dias) }\end{array}$ & $\begin{array}{c}\mathrm{S}_{\text {in }} \\
\left(\mathrm{MJ} \mathrm{m}^{-2} \mathrm{dia}^{-1}\right)\end{array}$ & $\begin{array}{c}\mathrm{S}_{\text {out }} \\
\left(\mathrm{MJ} \mathrm{m}^{-2} \mathrm{dia}^{-1}\right)\end{array}$ & $\begin{array}{c}\mathrm{L}_{\text {net }} \\
\left(\mathrm{MJ} \mathrm{m}^{-2} \mathrm{dia}^{-1}\right)\end{array}$ \\
\hline VE-Vn (\%) & 46 & $2,40^{* *}(14,7)$ & $1,55^{\star *}(95,5)$ & $-2,53^{\star *}(152,5)$ \\
\hline R1-R2 (\%) & 10 & $3,15^{* *}(21,5)$ & $2,31^{* *}(162,5)$ & $-2,04^{* *}(154,3)$ \\
R3-R4 (\%) & 15 & $2,33^{* *}(14,7)$ & $2,48^{* *}(166,2)$ & $-1,73^{* *}(102,9)$ \\
R5 (\%) & 25 & $2,69^{* *}(17,4)$ & $2,45^{* *}(168,8)$ & $-1,60^{* *}(80,8)$ \\
R6 (\%) & 14 & $0,88^{\text {ns }}(4,9)$ & $1,69^{* *}(100,6)$ & $-1,68^{\star *}(71,9)$ \\
R7-R8 (\%) & 15 & $0,83^{\text {ns }}(4,5)$ & $1,16^{* *}(64,66)$ & $-2,31^{* *}(91,1)$ \\
Média (\%) & & $2,04(12,9)$ & $1,94(126,4)$ & $-1,98(108,9)$ \\
\hline
\end{tabular}

Diferença $=$ Soja - Floresta; $(\%)=($ Soja-Floresta $) /$ Floresta. ${ }^{* *}=$ Significativo ao nível de $1 \%$ pelo teste t. ns $=$ não significativo

A presença de nuvens pode também ter contribuído para os menores valores de saldo de ondas longas na floresta por apresentar maior contra-radiação em função de uma atmosfera mais úmida (Silva Dias et al. 2005; Silva Dias 2006). O impacto negativo no saldo de ondas longas foi sempre superior a $71,9 \%$, com diferenças absolutas ao longo do ciclo da soja entre -1,6 e -2,53 $\mathrm{MJ} \mathrm{m}^{-2} \mathrm{dia}^{-1}$ comparativamente aos valores da floresta.

O impacto acumulado diariamente no saldo de radiação ao longo do ciclo da soja foi de $-237 \mathrm{MJ} \mathrm{m}^{-2} \mathrm{em} 2006$ e de $-247 \mathrm{MJ} \mathrm{m}^{-2}$ em 2007. Esta redução representa um impacto médio negativo de $16,6 \%$ no valor original disponível na floresta Amazônica referente aos dois anos estudados, podendo, no entanto, haver variaçóes interanuais que não foram consideradas no estudo pela limitação de dados para a pesquisa. Von Randow et al. (2004) encontraram um impacto negativo médio anual de $13,3 \%$ no saldo de radiaçáo devido à substituição da floresta para pastos na Amazônia. O impacto observado por Von Randow et al. (2004) é menor devido aos fatores morfológicos relacionados a tipo de cobertura foliar (pastagem), que neste caso, apresentou menor albedo comparado a algumas fases da cultura da soja, reduzindo a perda de energia na superfície. A diferença obtida entre os estudos $(3,3 \%)$ equivaleria a uma quantidade adicional de $17,6 \mathrm{~mm}$ de evapotranspiração na regiáo de pastagem, valor baixo considerando o volume de água envolvido no ciclo hidrológico da regiáo nesta época do ano. 
Usando modelos de circulação da atmosfera (ETA/SSiB) com diferentes mapas de vegetação da Amazônia, Alvalá et al. (2007) encontraram uma reduçáo no saldo de radiação durante o período chuvoso na Amazônia variando entre 12,9 e $15,4 \%$ para um cenário atual e futuro de desmatamento para o cultivo de pastagem, respectivamente.

Em termos médios, nota-se uma redução de até 2,23 $\mathrm{MJ} \mathrm{m} \mathrm{mia}^{-1}$ de energia ao longo do ciclo da soja (Tabela 2). No ano de 2006 o maior impacto observado correspondeu a uma redução de $21,1 \%$ no saldo de radiação durante a fase de enchimento de gráos (R5), momento em que, segundo Souza et al. (2011), a soja possui elevada evapotranspiração, e cobertura plena do solo. Nos demais períodos o impacto negativo variou entre 13 e $19 \%$.

Tabela 2 - Impactos negativos diários médios e relativos no saldo de radiação em cada fase da soja na Amazônia.

\begin{tabular}{|c|c|c|c|c|c|c|}
\hline \multirow[t]{2}{*}{ Fases } & \multicolumn{2}{|c|}{$\begin{array}{l}\text { Impacto Diário } \\
\left(\mathrm{MJ} \mathrm{m}^{-2} \text { dia }^{-1}\right)\end{array}$} & \multicolumn{2}{|c|}{$\begin{array}{l}\text { Impacto relativo } \\
(\%)\end{array}$} & \multirow{2}{*}{$\begin{array}{c}\text { Médio diário } \\
\left(\mathrm{MJ} \mathrm{m}^{-2} \mathrm{dia}^{-1}\right)\end{array}$} & \multirow{2}{*}{$\begin{array}{c}\text { Médio relativo } \\
\text { (\%) }\end{array}$} \\
\hline & 2006 & 2007 & 2006 & 2007 & & \\
\hline VE-Vn & $\begin{array}{c}1,94^{* *} \\
( \pm 0,40)\end{array}$ & $\begin{array}{l}2,19^{* *} \\
( \pm 0,62)\end{array}$ & 15,0 & 15,5 & $\begin{array}{c}2,08^{* *} \\
( \pm 0,41)\end{array}$ & 15,5 \\
\hline $\mathrm{R} 1-\mathrm{R} 2$ & $\begin{array}{c}1,86^{*} \\
( \pm 1,05)\end{array}$ & $\begin{array}{c}2,08^{\mathrm{ns}} \\
( \pm 0,99)\end{array}$ & 15,6 & 16,2 & $\begin{array}{c}1,97^{* \star} \\
( \pm 0,70)\end{array}$ & 15,6 \\
\hline R3-R4 & $\begin{array}{c}1,79^{* *} \\
( \pm 1,02)\end{array}$ & $\begin{array}{c}1,69^{\star} \\
( \pm 0,65)\end{array}$ & 13,7 & 13,4 & $\begin{array}{c}1,73^{* *} \\
( \pm 0,55)\end{array}$ & 13,5 \\
\hline R5 & $\begin{array}{c}2,68^{* *} \\
( \pm 0,42)\end{array}$ & $\begin{array}{c}1,15^{\star *} \\
( \pm 0,64)\end{array}$ & 21,1 & 9,1 & $\begin{array}{c}1,83^{* *} \\
( \pm 0,51)\end{array}$ & 14,3 \\
\hline R6 & $\begin{array}{l}2,50^{* *} \\
( \pm 0,71)\end{array}$ & $\begin{array}{c}3,44^{* *} \\
( \pm 0,51)\end{array}$ & 18,3 & 24,6 & $\begin{array}{l}2,93^{* *} \\
( \pm 0,45)\end{array}$ & 21,2 \\
\hline R7-R8 & $\begin{array}{c}2,39^{* *} \\
( \pm 0,72)\end{array}$ & $\begin{array}{c}3,43^{* *} \\
( \pm 0,54)\end{array}$ & 17,1 & 23,3 & $\begin{array}{l}2,86^{* *} \\
( \pm 0,47)\end{array}$ & 19,9 \\
\hline Média & $\begin{array}{c}2,19 \\
( \pm 0,15)\end{array}$ & $\begin{array}{c}2,33 \\
( \pm 0,29)\end{array}$ & $\begin{array}{c}16,8 \\
( \pm 1,27)\end{array}$ & $\begin{array}{c}17,4 \\
( \pm 1,82)\end{array}$ & $\begin{array}{c}2,23 \\
( \pm 0,21)\end{array}$ & $\begin{array}{c}16,6 \\
( \pm 1,21)\end{array}$ \\
\hline
\end{tabular}

Valores em parênteses representam erro padrão de estimativa. ${ }^{*}=$ significativo ao nível de $5 \%$ pelo teste t. ${ }^{*}=$ significativo ano nível de $1 \%$ pelo teste t. ${ }^{\text {ns }}=$ não significativo.

No ano de 2007 a redução média no saldo de radiação foi maior do que em 2006 pelo fato deste ano ter sido menos chuvoso, onde a soja apresentou menor IAF e maior exposição do solo mantendo um albedo mais elevado durante um período maior do que em 2006 (Souza et al. 2008).

Um dos problemas de ordem climatológica em relaçáo ao uso da terra para fins agrícolas na Amazônia é a contínua mudança na arquitetura do dossel, o qual modifica a resistência aerodinâmica da superfície com o crescimento da cultura, a mudança no seu albedo, e consequentemente na perda de energia por ondas longas ao longo do ciclo da cultura, tendo como resultado um impacto muito maior nos processos de trocas gasosas entre a superfície e atmosfera durante um único período do ano.
Sakai et al. (2004) também constataram o efeito da dinâmica da vegetaçáo no balanço radiativo e energético em uma área com rotação de pastagem-solo nu-arroz, ao contrário do observado em uma floresta próxima a área de estudo, onde o saldo de radiaçáo foi dependente apenas do grau de nebulosidade. Resultados obtidos por Pongratz et al. (2006) baseados em modelagem local mostram que os impactos gerados pela substituição da floresta por outro tipo de superfície são controlados por uma combinação de fatores relacionados a morfologia e fisiologia da superfície, o que resulta em diferentes impactos dependendo do tipo de cobertura vegetal a ser considerada no uso da terra.

O principal problema dos modelos de circulação geral e de meso-escala está no fato de não considerar esta dinâmica que ocorre ao longo do tempo, o que pode comprometer a veracidade dos resultados simulados. Sampaio et al. (2007) simularam uma reduçâo no saldo de radiação de apenas 2,8\% ao considerar que $20 \%$ da Amazônia seja substituída por soja e de $7 \%$ para casos em que toda a floresta é substituída para o plantio da soja. Entretanto, os resultados obtidos por Sampaio et al. (2007) referem-se a uma escala espacial diferente dos resultados observacionais (locais) encontrados nesta pesquisa. Os impactos encontrados ao se comparar pontualmente os dois tipos de ecossistemas são maiores, pois não consideram possíveis efeitos de feedback gerados por diferentes interaçōes no sistema solo-planta-atmosfera (Betts et al. 2007), fato este comumente considerado na modelagem de grande escala, tendo como conseqüência, uma suavização dos impactos observados localmente.

\section{Impactos durante a entressafra}

Nos recentes trabalhos sobre os possíveis impactos da substituiçáo da floresta natural pela cultura da soja, as análises têm se restringido ao período de desenvolvimento da cultura, não sendo consideradas as mudanças nas trocas de superfície durante o período da entressafra. Enquanto o ciclo da cultura tem duraçáo de $1 / 3$ do ciclo sazonal (ano) a entressafra tem duraçáo dos outros $2 / 3$, devendo, portanto, de maneira geral, ser importante para definir os impactos no balanço de radiação.

A Figura 3 apresenta as médias a cada 10 dias dos componentes do balanço de radiaçáo após a colheita da soja em 2007, e valores médios observados no mesmo período no ecossistema florestal, ambos a partir do mês de junho, época comum para a realização da colheita da soja na região. A falta de dados durante a entressafra de 2006 na área de produção de soja impossibilitou a comparação entre os dois ecossistemas neste ano.

Durante a entressafra observa-se um aumento relativo de todos os componentes do balanço de radiação comparado ao 
período do ciclo da cultura em ambos os ecossistemas. Este fato pode ser constatado ao se comparar as magnitudes da energia disponível na Figura 3 com a Figura 1. Este aumento sazonal está de acordo com a maioria dos resultados encontrados nos trabalhos sobre balanço de radiação em outros tipos de ecossistemas vegetais na Amazônia, estando associado à variabilidade na disponibilidade de água no solo e ao grau de nebulosidade (Galvão e Fisch 2000; Von Randow et al. 2004, Souza Filho et al. 2006).

De forma análoga ao período de crescimento da soja, nota-se uma significativa diferença nos componentes radiativos entre os dois ecossistemas, principalmente em relação à componente refletida e ao saldo de ondas longas (Figura 3B e $3 \mathrm{C}$ ). A quantidade de radiação refletida na floresta apresentou pouca variação $\left(\approx 2,5 \mathrm{MJ} \mathrm{m}^{-2} \mathrm{dia}^{-1}\right)$, o que representou um albedo médio entre 0,10 e 0,12 (Figura 3B).

Carswell et al. (2002) também observaram esta sazonalidade no albedo de Caxiuanã cujos valores variaram de 0,09 a 0,12 respectivamente nos períodos chuvoso e menos chuvoso do ano na região. Esta variação no albedo foi associada à secagem do dossel da floresta. Souza Filho et al. (2006) encontraram para este mesmo ecossistema florestal uma variação entre período chuvoso e menos chuvoso de 8,2 para $11,9 \%$ no albedo e de -1,4 para $-2,8 \mathrm{MJ} \mathrm{m}^{-2} \mathrm{dia}^{-1}$ para o saldo de ondas longas, respectivamente. A variaçáo observada no saldo de ondas longas na floresta entre o período de produção de soja e a entressafra com dados de 2007 foi de $-1,9$ a $-3,2 \mathrm{MJ} \mathrm{m}^{-2}$ $\mathrm{dia}^{-1}$, respectivamente. Diferentes séries de dados no computo da média e o fato de o saldo de onda longa ter sido obtido como resíduo no balanço podem ter contribuído para esta pequena diferença em relação à literatura, havendo, porem, a sazonalidade.

Diferentemente do que ocorre durante o ciclo da soja, onde o saldo de ondas longas sofre influência da cobertura vegetal, durante a entressafra a perda por ondas longas na área de produçâo de soja apresenta pouca variaçáo, sendo $2 \mathrm{MJ} \mathrm{m}^{-2}$ $\mathrm{dia}^{-1}$ superior ao observado durante o ciclo. Com a redução na cobertura do solo na área de agricultura, a exposição do solo tem como conseqüência um aumento significativo da sua temperatura intensificando ainda a mais a emissão de ondas longas pela superfície (Souza Filho et al. 2006)

A perda de energia por ondas longas na floresta durante este período também é bem menor do que na área de produção de soja. A intensificação desta perda de energia na forma de ondas longas em ambos os ecossistemas nesta época do ano, pode estar também diretamente associado à redução na componente atmosférica decorrente da diminuiçáo no grau de nebulosidade em ambos os locais (Figura 2).

O saldo global de radiação na área de cultivo de soja aumenta gradualmente durante a entressafra permanecendo em torno de $12,5 \mathrm{MJ} \mathrm{m}^{-2} \mathrm{dia}^{-1}$ após os $40 \mathrm{DAC}$ até em torno de 110 DAC (Figura 3D), um pouco acima do valor observado

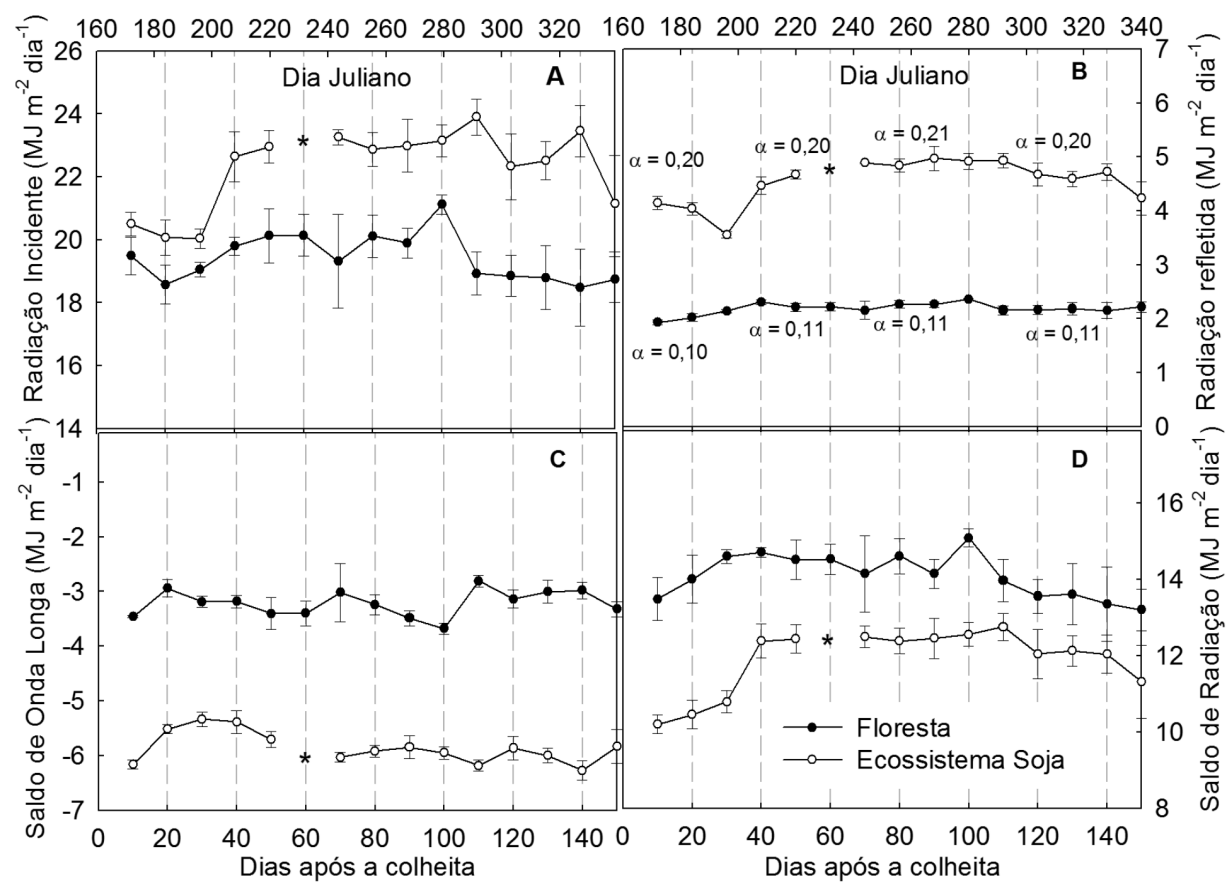

Figura 3 - Média decendial do ano de 2007 dos componentes do balanço de radiação na entressafra da área de produção da soja e no período correspondente no ecossistema de floresta. As barras verticais representam o erro padrão; $\alpha=$ albedo. ( ${ }^{*}=$ falha na coleta de dados). 
durante o ciclo da cultura, sendo também menor do que o observado na floresta. Percebe-se após os 110 DAC (dia Juliano 282), uma tendência de diminuição no saldo de radiação em ambos os locais, provavelmente associado à redução observada na radiação incidente (Figura 3A) decorrente do início do período chuvoso na regiáo. Até cerca de 30 DAC, o impacto médio no saldo de radiaçáo associado ao sistema de produção de soja na Amazônia é de aproximadamente 25,3\%, representando uma diferença média absoluta em torno de $3,73 \mathrm{MJ} \mathrm{m}^{-2} \mathrm{dia}^{-1}$.

Durante a entressafra quando o albedo permaneceu em torno de 0,20 , o efeito da reduçáo tanto na nebulosidade como na cobertura do solo no ecossistema agrícola, intensificou a perda por ondas longas, reduzindo ainda mais a energia disponível neste local. Resultados semelhantes foram obtidos por Alvalá et al. (2007), os quais atribuíram o aumento do impacto no saldo de radiação durante o período seco da Amazônia devido à substituiçáo da floresta para pastagem como sendo devido ao aumento na perda por ondas longas na pastagem.

Entretanto, este aumento sazonal só foi observado no primeiro mês pós-colheita, pois embora tenha ocorrido maior impacto no saldo de ondas longas durante toda a entressafra, o aumento na radiação solar incidente após os 30 DAC favoreceu o aumento do saldo de radiação que por sua vez teve pouca influencia do albedo da superfície por ser invariável e menor que o observado durante o ciclo.

A partir dos 40 até antes dos 110 DAC nota-se uma contínua redução deste impacto. Esse menor impacto neste período resulta do decréscimo no saldo de radiaçáo na floresta gerado pela diminuição na radiação incidente, uma vez que nesta mesma época o saldo de radiaçáo permaneceu praticamente constante no ecossistema de soja (menor nebulosidade). Durante este período da entressafra (40-100 DAC), o impacto médio encontrado no saldo de radiaçáo foi de $14,3 \%$.

O impacto existente no saldo de radiação nos primeiros três meses de entressafra da soja correspondeu em média a $18,1 \%$ do valor existente na floresta, superior ao valor médio encontrado durante o ciclo (16,6\%). Por outro lado, ao se considerar todo período de entressafra, o impacto médio no saldo de radiação reduz para $15,5 \%$.

Os impactos no saldo de radiação reportados para períodos semelhantes em casos de uso da terra para pastos são de 11,4\% para os meses de agosto a novembro (Von Randow et al. 2004). Alvalá et al. (2007) simularam para a época seca da Amazônia, um impacto no saldo de radiação de $16,6 \%$ considerando um cenário atual de desmatamento para fins de pastagem.
A Tabela 3 apresenta um resumo geral com os reais valores dos impactos observados ao longo do sistema de produção da soja na Amazônia. Ressalta-se que embora o maior impacto ocorra durante o período de crescimento da cultura, o tempo de ocorrência deste efeito se dá apenas durante cerca de $1 / 3$ do tempo do ciclo sazonal (ano), enquanto que os $2 / 3$ restantes estariam relacionados à um impacto médio de $15,5 \%$ no saldo de radiação do ambiente.

O impacto anual médio no saldo de radiação encontrado foi de $15,8 \%$, próximo do encontrado por Alvalá et al. (2007) para o caso da pastagem. Por outro lado, este resultado difere dos $7 \%$ obtidos por Sampaio et al. (2007) com 100\% de substituição da floresta por soja, demonstrando a necessidade de uma melhor parametrização e calibração do modelo utilizado uma vez que não representam de forma fiel as interaçôes que ocorrem no ecossistema de soja.

Mudanças no padrão de uso da terra levam a diferentes interaçôes no sistema solo-planta-atmosfera, uma vez que não apenas fatores de rugosidade da superfície como a resistência aerodinâmica ao transporte de vapor d'água, como também fatores fisiológicos em função do tipo de cobertura (planta do tipo $\mathrm{C}_{3}$ ou $\mathrm{C}_{4}$ ) modificam o transporte de vapor para a atmosfera (Pongratz et al. 2006). Com a redução no saldo de radiação à superfície decorrente da substituição da floresta por qualquer outro tipo de cobertura, espera-se que haja uma mudança no consumo da energia disponível na forma de calor sensível e latente (Von Randow et al. 2004; Sampaio et al. 2007).

No entanto, ao contrário do que se supóe, a cobertura com soja chegou a evapotranspirar mais do que o ecossistema florestal durante algumas fases de ciclo da cultura, devido a fatores como elevado IAF, e elevada condutância do dossel a qual pode atingir picos de $0,10 \mathrm{~m} \mathrm{~s}^{-1}$ durante o ciclo (Souza $e t$ al. 2011), enquanto que o maior valor observado por Carswell et al. (2002) para Caxiuanã não ultrapassou $0,06 \mathrm{~m} \mathrm{~s}^{-1}$. Tal fato está relacionado a impactos médios negativos não significativos no fluxo de calor latente para a atmosfera durante o período de crescimento quando comparados a ecossistemas naturais

Tabela 3 - Impacto relativo médio nos componentes do balanço de radiação durante 0 ciclo da soja e no período de entressafra na Amazônia.

\begin{tabular}{lcccc}
\hline Período & $\mathrm{S}_{\text {in }}$ & $\mathrm{S}_{\text {out }}$ & $\mathrm{L}_{\text {net }}$ & $\mathrm{R}_{\text {net }}$ \\
\hline \multirow{3}{*}{ Ciclo } & $(\%)$ & $(\%)$ & $(\%)$ & $(\%)$ \\
& $12,9^{* *}$ & $126,4^{* *}$ & $108,9^{* *}$ & $16,6^{* *}$ \\
\multirow{2}{*}{ Entressafra } & $( \pm 2,8)$ & $( \pm 18,4)$ & $( \pm 14,7)$ & $( \pm 1,2)$ \\
& $15,0^{* *}$ & $108,6^{* *}$ & $83,8^{* *}$ & $15,5^{* *}$ \\
\hline
\end{tabular}

Valores em parênteses representam erro padrão de estimativa. * $=$ significativo ao nível de $5 \%$ pelo teste t. ${ }^{* *}=$ significativo ano nível de $1 \%$ pelo teste t. ${ }^{\text {ss }}=$ não significativo. 
pelo fato de haver maior fluxo de calor latente em algumas fases do ciclo.

Entretanto, é importante lembrar que diferentes impactos podem ser esperados em função do grau de substituição da superfície como conseqüência das várias interaçôes e feedbacks gerados (Costa e Yanagi 2006; Betts et al. 2007) como também em função do tipo de cobertura vegetal que sucede o uso da terra (Pongratz et al. 2006).

A simulação dos impactos no balanço de radiação devido o avanço da soja obtida por Costa et al. (2007) e Sampaio et al. (2007) diferem do que foi observado localmente devido a diferença de escala espacial dos trabalhos, mas ambos apontam impactos significativos no saldo de radiaçáo devido a substituição da floresta por soja.

\section{CONCLUSÕES}

A diferença observada entre os dois tipos de ecossistemas indicam haver uma reduçáo na disponibilidade de energia à superfície como conseqüência das mudanças na arquitetura da cobertura do solo ao longo do tempo. Devido ao manejo comumente adotado na região para a entressafra no sistema de produção da soja, observa-se um importante aumento relativo na radiação refletida pela superfície comparada à floresta pelo fato do albedo da superfície manter-se elevado $(0,20)$ neste período.

Embora a perda de energia por ondas longas seja reduzida com o crescimento da cultura, o aumento no albedo da superfície contribui significativamente para o impacto observado. Entretanto, pela própria distancia entre os dois sítios experimentais, fatores de ordem local podem ter contribuído para esta diferença.

Apesar do impacto observado durante o período de entressafra ser menor do que o observado durante o período de crescimento da soja, o seu efeito cumulativo pode ser mais intenso pelo fato de durar $2 / 3$ do ano.

\section{AGRADECIMENTOS}

Os autores agradecem ao CNPQ pelo financiamento da pesquisa através do projeto CTHIDRO (processo $\left.\mathrm{n}^{\circ} 552738 / 2005-0\right)$ e ao projeto CARBO-PARÁ por disponibilizar os dados referentes ao ecossistema de floresta. $O$ primeiro autor também agradece à CAPES pela concessão da bolsa de doutorado.

\section{BIBLIOGRAFIA CITADA}

Alvalá. R.C.S.; Correia, F.W.S.; Manzi, A.O. 2007. Modelagem dos impactos das mudanças da cobertura da terra na Amazônia: Avaliação do balanço de radiação. In: XIII Simpósio Brasileiro de Sensoriamento Remoto, Florianópolis. Anais..., p.6573-6570.
Berbet, M.L.C.; Costa, M.H. 2003. Climate change after tropical deforestation: seasonal variability of surface albedo and its effects on precipitation change. Journal of Climate, 16: 2099-2104.

Betts, A.K.; Desjardins, R.L; Worth, D. 2007. Impact of agriculture, forest and cloud feedback on the surface energy budget in BOREAS. Agriculture and Forest Meteorology, 142: 156-169.

Carswell, F.E.; Costa, A.C.L.; Palheta, M.; Malhi, Y.; Meir, P.; Costa, J.P.R.; Ruivo, M.de L.; Leal, L.do S.M.; Costa, J.M.N.; Clement, R.J.; Grace, J. 2002. Seasonality in CO2 and H2O flux at an eastern Amazonian rain forest. Journal of Geophysical Research, 107(D20): 1-16.

Cohen, J.C.P.; Beltrão, J.C.; Gandu, A.W.; Silva, R.R. 2007. Influência do desmatamento sobre o ciclo hidrológico da Amazônia. Ciência e Cultura, 59(3): 36-39.

Correia, F.W.S.; Alvalá. R.C.S.; Manzi, A.O. 2006. Impacto das modificaçóes da cobertura vegetal no balanço de água na Amazônia: um estudo com modelo de circulaçáo geral da atmosfera (MCGA). Revista Brasileira de Meteorologia, 21(3a): 153-167.

Costa, M.H.; Foley, J.A. 2000. Combined effects of deforestation and doubled atmospheric $\mathrm{CO}_{2}$ concentrations on the climate of Amazonia. Jornal of Climate, 13: 18-34.

Costa, M.H.; Yanagy, S.M.N. 2006. Effects of Amazon deforestation on the regional climate - historical perspective, current and future research. Revista Brasileira de Meteorologia, 21(3a): 200211.

Costa, M.H.; Yanagy, S.M.N; Ponte de Souza, P.J.O; Ribeiro, A.; Rocha, E.J.P. 2007. Climate change in Amazonia caused by soybean cropland expansion, as compared to caused by pastureland expansion. Geophysical Research Letters, 34: L07706.

Fearnside, P.M. 2001. Soybean cultivation as a threat to the environment in Brazil. Environmental Conservation, 28(1): 23-28.

Fehr, W.R.; Caviness, C.E.; Burmood, D.T.; Pennington,J.S. Stage of development descriptions for soybeans, Glycine max (L.) Merrill. Crop Science, 11: 929-931, 1971.

Fontana, D. C.; Berlato, M.A.; Bergamashi, H. 1991. Balanço de energia em soja irrigada e não irrigada. Pesquisa Agropecuária Brasileira, 26(3): 403-410.

Galvão, J.A.C.; Fisch, G. 2000. Balanço de radiação em área de pastagem na Amazônia. Revista Brasileira de Agrometeorologia, 8(1): $1-10$.

Giambelluca, T.W.; Holscher, D.; Bastos, T.X.; Frazão, R.R.; Nullet, M.A.; Zielger, A.D. 1997. Observations of albedo and radiation balance over postforest land surfaces in the eastern Amazon basin. Journal of Climate, 10: 919-928.

Querino, C.A.S.; Moura, MA.L.; Lyra, R.F.F.; Mariano, G.L. 2006. Avaliação e comparação de radiação solar global e albedo com ângulo zenital na região Amazônica. Revista Brasileira de Meteorologia, 21(3a): 42-49.

Pongratz, J.; Bounoua, L.; DeFries, R.S.; Morton, D.C.; Anderson, L.O. 2006. The impact of land cover change on surface energy 
and water balance in Mato Grosso, Brazil. Earth Interactions, 10(19): 1-17.

Sakai, R.K.; Fitzjarrald, D.R.; Moraes, O.L.L.; Staebler, R.M.; Acevedo, O.C.; Czikowsky, M.J.; Silva, R.; Brait, E.; Miranda, V. 2004. Land-use change effects on local energy, water, and carbon balances in an Amazonian agricultural field. Global Change Biology, 10: 895-907.

Sampaio, G.; Nobre, C.; Costa, M.H..; Satyamurt, P.; Soares-Filho, B.S.; Cardoso, M. 2007. Regional climate change over eastern Amazonia caused by pasture and soybean cropland expansion. Geophysical Research Letters, 34: (L17709):1-7.

Silva Dias, M.A.F.; Cohen, J.C.P.; Gandu, A.W. 2005. Interaçōes entre nuvens, chuvas e a biosfera na Amazônia. Acta Amazônica, 35(2): 215-222.

Silva Dias, M.A.F. 2006. Meteorologia, desmatamento e queimadas na Amazônia: uma síntese de resultados do LBA. Revista Brasileira de Meteorologia. 21(3a): 190-199.

Simon, M.F.; F.L. Garagorry. 2005. The expansion of agriculture in the Brazilian Amazon. Environmental Conservation, 32(3): 203-212.

Souza, P.J.O.P.; Rocha, E.J.P.; Ribero, A.; Loureiro, R.S.; Bispo, C.J.C. 2008. Impactos no albedo em conseqüência do avanço da fronteira agrícola na Amazônia. Revista Brasileira de Agrometeorologia, 16(1): 87-95.
Souza, P.J.O.P.; Ribeiro, A.; Rocha, E.J.P.; Loureiro, R.S.; Bispo, C.J.C. 2010. Albedo da cultura da soja em área de avanço da fronteira agrícola na Amazônia. Revista Brasileira de Engenharia Agricola e Ambiental, 14(1): 65-73.

Souza, P.J.O.P.; Ribeiro, A.; Rocha, E.J.P.; Botelho, M.N.; Sousa, A.M.L.; Souza, E.B.; Farias, J.R.B. 2011. Impacts of Soyabean expansion on the Amazon energy balance: a case study. Experimental Agriculture, 47(3): 553-567.

Souza Filho, J.D.C.; Ribeiro, A.; Costa, M.H.; Cohen, J.C.P.; Rocha, E.J.P. 2006. Variaçáo sazonal do balanço de radiação em uma floresta tropical no nordeste da Amazonia. Revista Brasileira de Meteorologia, 21(3b): 318-330.

Von Randow, C.; Manzi, A.O.; Kruijt, B.; Oliveira, P.J.; Zanchi, F. B; Silva, R.L.; Hodnett, M.; Gash, J.; Elbers, J. A.; Waterloo, M. 2004. Comparative measurements and seasonal variations in energy and carbon exchange over forest and pasture in south west Amazonia. Theoretical and Applied Climatology, 78: 5-26.

Recebido em:17/01/2012

Aceito em: 28/06/2012 